\title{
Reformando o ensino de História: lições de continuidade
}

Elaine RODRIGUES

R E SU M 0: Este artigo objetiva trabal har o ensino de História focando a problemática da continuidade em seus conteúdos. A problematização situou o tema em dois momentos representativos da História do Brasil. 0 primeiro período, ditatorial, é apresentado por meio dos objetivos da disciplina Educação M oral e Cívica. O segundo, pós-abertura política, é caracterizado por uma democracia (re)nascente e é demonstrado apresentando-se o Projeto Político-Pedagógico do Estado do Paraná e as expectativas depositadas por ele no ensino de História. M etodologicamente, trabalhamos de forma comparativa. Os resultados obtidos consideraram que o caminho percorrido demonstra que é falaciosa a idéia de que houve uma ruptura com a forma e com os conteúdos do ensino deH istória eapontam queestá nas mãos dos professores compromissados com sua nação a possi bilidade detransformá-la. Foram eleitos como fontes o Jornal da Educação, o Decreto-Lei de criação da disciplina Educação Moral e Cívica, o Projeto Pedagógico e o Currículo básico para a escola pública do Paraná.

Pa Lav r a S-c c h Av E : História; Ensino deHistória; Educação M oral eCívica.

A apresentação inicial de questões panorâmicas afetas à educação justifica-se por constituir um desafio a tarefa de tratar problemas específicos de ensino de forma correspondente àqueles que se caracterizam como "gerais".

A sociedade contemporânea caracteriza-se por apresentar um caráter heterogêneo. Somos educadores em um universo de diversidades culturais e políticas, o qual impõe ao professor o desafio de construir, forjar, criar, inventar seu trabalho, respeitando-o e inserindo-se em suas multifaces. As muitas facetas do universo social criam um complexo labirinto e, como é próprio de sua configuração, seus caminhos são entre- 
cortados, bloqueados, enganosos, apresentando inúmeras possibilidades para ser percorridos. As muitas formas de interpretação do caminho triIhado ou ainda por trilhar no interior do labirinto é que produzem a riqueza que não somente pode como também devefazer parte do ato de ensinar e de refletir sobre a ação realizada. Tal vez seja esta a saída: o respeito, por parte do pesquisador educacional, à idéia de quetrabalhamos com um objeto, a educação, que se compõe e recompõe em suas inúmeras representações, e o ensino de História aí se integra.

Um dos pontos importantes e merecedores de destaque foi problematizado a partir da constatação de que vivemos eatuamos na sociedade da velocidade. ${ }^{2}$ Sua forma, amparada em um grandioso aparato técnico, disponibiliza grande quantidade de informações, imprimindo um ritmo frenético a todas as instâncias do então denominado meio social, de forma a criar uma dinâmica que exige hábitos, padrões, e uma diferente percepção do mundo que cerca a vida e compõea ação docente.

Os comportamentos, no âmbito pessoal ou no âmbito profissional, são atitudes que têm como referência uma dada noção de tempo, que sinalizam como sentir, do que falar, qual a melhor linguagem para atingir o receptor, o que ensinar, e isso vai definindo uma dada forma de conhecer e de se reconhecer sujeito nas ações. São princípios comportamentais definidores de um conjunto de atitudes que, ao tentar acompanhar esse novo ritmo, tem perdido seus balizadores. Tal ritmo requer a incorporação de uma outra dimensão temporal, o que faz com que os acontecimentos não resistam, não se condensem, pois não há "tempo" para se pensar em como ser ou agir, e é preciso atender à demanda. Essa éa "demanda"!

Cultura alguma resiste a essa "centrifugação"; da mesma forma, a realidade singular da sala de aula e dos sistemas de ensino não resistem à sua verificação, à sua avaliação. A verificação dosfatos se dá, émedida ou não, quanto a suportar os efeitos dessa velocidade. A noção de temporalidade, que permite a formulação dos sistemas de ensino, da realidade singular da sala de aula é a do relógio, do calendário, e a que vivenciamos pode ser representada pela Internet, uma realidade virtualmente construída e instantaneamente desfeita.

Formulações teóricas baseadas na "temporalidade do calendário" e traduzidas em projetos, neste caso em particular pedagógicos, não estão 
em estado de refletir qualquer coisa. Existe a necessidade de uma certa lentidão para que se produza uma espécie de condensação, de cristalização significativa dos acontecimentos; o contrário disso são os efeitos dessa aceleração, que têm produzido uma demanda à qual, como professores, tentamos atender. Essa tentativa tem dirigido as ações, tem encaminhado o planejamento estrutural de um curso ou de uma disciplina, procurando adequá-lo, articulá-lo a essa realidade.

Por outro lado, evidências empíricas ao alcance de pais, professoresealunosmostram que a escola está a reboque da sociedade. 0 discurso articulado, como tentativa de estímulo à mudança dessequadro, apresenta sentenças afirmativas que remetem o professor a um fazer pedagógico que tenha como proposta educacional atingir o desenvolvimento integral e harmonioso de todas as capacidades do indivíduo. Paradoxalmente, a prática educativa tem se revelado um processo de adestramento sel etivo da "formação desi", o queconstitui uma domesticação. Educação tem sido sinônimo de tornar o cidadão dócil, frágil e obediente aos valores em curso. ${ }^{3}$ Adestrar significa formar o indivíduo para obedecer a regras e incorporar novos hábitos; então, qual o papel da boa escola na sociedade da velocidade?

Diante do princípio de que educar tem sido adestrar, o papel de uma boa escola seria moldar o estudante, adequando-o, conformando-o como agente articulador em sua sociedade esua cultura. Tomando por princípio essa vertente analítica, a educação tende a criar o homem teórico como modelo do resultado das práticas educacionais, de um ideal de educação, de uma ilusão constituída sob o pretexto de formação crítica. M as uma nova educação deve contemplar a formação de novos hábitos? Isto significaria construir uma nova natureza? Pressupõe-se que durante o processo educacional o aluno consiga desfazer-se de sua primeira natureza? Deve abandonar os hábitos antigos de pensar e de ser? O que caracteriza o homem adestrado, na sociedade da velocidade?

Enquanto no panorama geral as discussões em torno da educação versam sobre temas de ordem filosófica, histórica, sociológica, em sala de aula o dilema do professor resume-se em manter a "disciplina", isto porque a escola deixou de ser o lugar do desafio na produção do conhecimento, o que obriga o professor a trabalhar impondo a ditadura da ordem e a disciplina do silêncio. A tarefa de ensinar acaba implicando, 
ainda que paradoxalmente, a destruição da liberdade. ${ }^{4}$ Afinal, qual é a liberdade possível na sociedade da velocidade?

É difícil responder a contento às questões formuladas porque não depende apenas de um maior número de leituras e de relações entre os estudos realizados, nem tampouco da capacidade individual de assumir esta ou aquela postura teórico-metodológica ou de abarcá-las, mesmo que insatisfatoriamente. I sso se faz possível pela inserção no debate sobre a formação do educando, sobre o ato de ensinar. M as ensinar o que? E a quem? A resposta será buscada pela focalização da problemática nas últimas décadas do século XX.

Esse período apresenta duas posturas com relação ao ensino de História e seus conteúdos, dois momentos representativos da H istória do Brasil. 0 primeiro, denominado período ditatorial, éapresentado neste estudo por meio dos objetivos da disciplina Educação Moral e Cívica. Faz-se necessário registrar sua relevância como esclarecedores dessa temática, por denotarem o grau de confiança, de poder atribuído ao ensino deH istória, embora sua nomeclatura seja retirada oficialmente dos currículos. Aparentemente a disciplina de Educação Moral e Cívica re presenta uma ruptura com a forma da disciplina e com os conteúdos anteriormenteensinados. Tal tesenão sesustenta, pois seusensinamentos, portadores de forte carga ideológica, caracterizaram-se por estimular a formação de um homem pacífico, moralmente correto, patriota, um cidadão súdito.

O espírito cívico imposto pelo Decreto-Lei n.869, de 12 de setembro de $1969,{ }^{5}$ visava à inclusão de Moral e Cívica como disciplina obrigatória nas escolas de todos os graus e modalidades dos sistemas de ensino no País. A intenção era inserir suas finalidades em todas as atividades escolares, inclusive no que diz respeito ao desenvolvimento dos atos cívicos, valorizados na prática educativa. As relações entre os valores humanos considerados superiores e a educação permitiriam que os cidadãos fossem integrados na sociedade, dela participantes como se fossem produtos culturais, como ilustrações no culto à nação, na identificação com a família e na dignidade do trabalho.

O propósito de inclusão da Educação Moral e Cívica seria, sinteticamente, a incorporação de seus ideais à sociedade, perpassando gerações, eisto deveria realizar-se como o próprio saber. A finalidadeda Edu- 
cação Moral eCívica seria de preparar o homem para a vida, esobretudo formar o cidadão para a sociedade, de acordo com as proposições do decreto que a criou.

Referir-se à formação do cidadão será admitir não ser possível realizá-la sem enfatizar a formação moral e cívica do educando para servir à sociedade e à família; sobressairão às atividades cívicas que - centradas no culto à nação - têm origem na valorização do caráter nacional. ${ }^{6}$

O segundo momento, que se configura como pós-abertura política, caracterizado por uma democracia ( re) nascente, édemonstrado quando apresento o Projeto Político-Pedagógico do Estado do Paraná e as expectativas que depositou no ensino de H istória. A análise da proposta paranaense, que pretendia "repensar os conteúdos básicos das disciplinas no que se refere aos aspectos teórico-metodológicos de cada área de conhecimento", 7 visa uma reflexão comparativa sobre os questionamentos aqui sistematizados.

A qualidade do ensino, no início da década de 1980, entendia a Secretaria de Estado da Educação do Paraná, vinculava-se à possibilidade da não reprodução da sociedade injusta tal como se apresentava: de um lado os que sabiam, e por deterem o conhecimento detinham também o poder, e de outro os que não sabiam e obedeciam ao poder. A qualidade de ensino vinculava-se à possibilidade de fazer com que a maioria da população pudesse dominar a soma de conhecimentosjá acumulados através dos tempos, para que todos pudessem, juntos, incumbir-se de criar uma nova sociedade.

0 enfoque dado à questão da mel hora na qualidade de ensino a ser oferecido pelo Estado estava no conteúdo a ser trabal hado. Uma proposta conteudista ${ }^{8}$ para a educação, que fixava suas bases naquilo que se ensinaria e não no modo como se ensinaria, tecendo críticas severas à visão tecnicista de educação e de ensino que era imperativa nos procedimentos didáticos de até então.

Especificamente relacionada ao campo disciplinar da História, a proposta paranaense propunha-se a desenvolver um trabalho em que ensinar História fosse sinônimo de educar para a cidadania democrática, tornando os jovens capazes de ação participativa. Em consonância 
com o período anterior, e não rompendo com ele, mantém-se o ideal de conformação dos sujeitos à nação no estado em que se encontrava, legitimando a ordem social e política, fosse ela ditatorial ou democrática. Tomadas como referência quer a disciplina de H istória, quer a disciplina de Educação M oral e Cívica não são diferentes; existe um processo contínuo de conformação de seus conteúdos ao ideal de formação do cidadão. A seleção de conteúdos, nas duas disciplinas, prima pela manutenção da tradição do ensino nacionalista e patriótico, calcado na H istória da civilização ocidental e no modelo eurocêntrico. Ainda buscamos o herói! Sendo "conservador" ou "revolucionário", a ele compete a tarefa de redimir a sociedade de seus males.

Houve, na década de 1980, uma tentativa de descartar o componente conservador da Educação Moral e Cívica, incorporando nos programas de História uma perspectiva mais comprometida com a participação democrática, por meio de um discurso que pretendia trabalhar com conteúdos mais significativos à sociedade. Os significados são construídos, e esta significação não é desarticulada dos interesses que a compõem e propõem. A questão se apresenta para além da intencionalidade grupal. Culturalmente somos frutos da mentalidade que engendrou os conteúdos de História na formação dos educandos no final do século XIX, cujo objetivo à época era legitimar a formação da Nação. No final do século XX, novas demandas surgiram e a escola as atendeu formando o seu educando "criticamente", atitude que, mais uma vez, o fazia adequado.

A parentemente um outro enovo ol har para a questão da qualidade de ensino parecia estar nascendo, pois se projetava em ações que exigiriam do educador assumir um compromisso político com a educação, por meio do ato de ensinar, e estes pressupostos se especificariam nos princípios por intermédio dos quais se ensinaria a H istória.

Conteúdos sociais, como aprender a lutar por seus direitos, eram entendidos pelos dirigentes educacionais como uma nova postura social, que também deveria estar à frente dos projetos educacionais, o que imputava à problemática da qualidade de ensino a responsabilidade pela melhoria do panorama geral da educação paranaense.

A Secretaria de Educação do Estado do Paraná passou a editar o Jornal da Educação; fazendo valer o espaço de comunicação que esta fo- 
Iha significava, lançou matérias para justificar o pedido de que novos comportamentosfossem assumidos pelos professores, diantede "velhos" e enraizados costumes.

Quando se trata da questão do rompimento com determinadas posturas ante os acontecimentos sociais, ou ante determinadas propostas pedagógicas para se ensinar determinados conteúdos, é importante nos reportarmos historicamenteà razão para que determinadas atitudes ocorressem ou quais eram as finalidades disciplinares, e aqui nos interessa o ensino da História no contexto escolar. A História, como disciplina escolar, sempretrabal hou com as noções de "I dentidade Nacional", "Cidadania", “Estado" e "Nação". Historicamente, o ensino de H istória foi marcado, em outros países e no Brasil, pelo ideal nacionalista.

0 ideal nacionalista permeou o período do governo militar no Brasil. Alguns $\operatorname{críticos}^{9}$ da escola na década de 1980 evidenciavam o golpe militar de 1964 e sua correspondente ação relativa ao aspecto educacional como um marco. 0 conteúdo das ciências humanas, e particularmente o da História, havia se esvaziado de seu aspecto crítico. A crítica e a contestação, características inerentes ao ensino de H istória, haviam se perdido, e era manifesto o seu caráter de instrumento de veiculação e formação do espírito cívico, entendido como aquele capaz de glorificar os feitos dos autoproclamados heróis do dia. ${ }^{10}$

Anteriormente a esse período, teria existido um ensino deH istória diferente do apregoado pelas disciplinas deO rganização Social ePolítica do Brasil e Educação Moral e Cívica, incluídas no currículo em substituição a ela. Da mesma forma, no período que se segue, momento de "abertura política no País", a crença éa de que a tarefa do educador seria romper com os ideais tradicionalmente presentes no ensino de H istória para construir uma escola democrática, uma escola que deixasse de formar o cidadão-súdito e passasse a construir um cidadão-participante. ${ }^{11}$

Uma dessas situações esteve relacionada a um dos conteúdos do ensino de História: as comemorações cívicas ligadas ao dia sete de setembro. 0 dia da Independência era tradicionalmente comemorado, no calendário escolar, com um "garboso" desfile, um culto à nação. Era um feito que se real izava para atender às expectativas de um projeto de ensino que visava à formação moral e cívica do educando, que compreendia a essência da nacionalidade, sintetizada em armas, brasões e símbolos, 
denotando as aspirações, militares, para a construção da nação brasileira com ordem, progresso e igualdade entre os homens. ${ }^{12}$

Se um decreto-lei inseriu na escola conteúdos de moral e de civismo, caracterizando um ato de determinação hierarquicamente superior einquestionável, no ano de 1983, em pleno processo de abertura política e finalização do regime militar, os professores, mais uma vez por determinação superior, foram avisados de que não mais seria necessário que 0 ato cívico acontecesse.

A Secretaria de Educação "sugeria" que as comemorações se dessem no interior da escola. Sobre as comemorações afetas à Semana da Pátria, as diretrizes propunham que esse momento passasse a ser considerado como um momento de reflexão em torno da questão da cidadania. $O$ ato cívico do Sete de Setembro passaria a ter características reflexivas que partiam do pressuposto de que a ação pedagógica deveria se dar aliada ao compromisso político do cidadão para com a nação.

Dentro do ideal democrático assumido e professado pela SEED Secretaria de Estado da Educação, no seu Projeto Pedagógico, ${ }^{13}$ todos os envolvidos no fazer educacional seriam responsáveis politicamente pela formação do cidadão, entendido como um ser capaz de conscientemente responder pelos seus atos.

Não mais seadmitia, segundo os princípios da SEED, que os participantes das comemorações falassem sobre as atividades que tivessem desenvolvido como se fossem alheios aos fatos, comportando-se como expectadores passivos no processo. 0 ato dequestionar, deemitir opiniões não era habitual no projeto político em que o professor estava, por costume, inserido. 0 ser civicamente instruído era um agente passivo, pois a passi vidadehavia sido estimulada duranteos anos demilitarismo como uma virtude. 0 cidadão, passivo ou ativo, continuava sendo requisitado como conformador de um ideal para a nação. Um ideal que culturalmente continuava a forjar heróis nacionais.

A Secretaria de Educação do Paraná, por meio do seu Projeto Político-Pedagógico, pedia uma participação consciente, livre, crítica e profunda, que fosse capaz de despertar professores, alunos e a comunidade para pensar eagir sobre a realidade. A passividadediantedos fatos representava um problema a ser discutido. Porém, a maior dificuldade para se conseguir desenvolver um projeto educacional que primasse pelo ensi- 
no de boa qualidade derivava, de acordo com a opinião dos dirigentes educacionais, precisamente da falta de uma metodologia, e das respectivas práticas elaboradas para essa tarefa.

O ensino de História ganhou especial destaque na proposta da SEED, e isto se deu por ter sido despertado, por intermédio dos conteúdos de Educação Moral e Cívica que se veiculava nas escolas, o ideal nacionalista militar. Pretendia-se, nos idos de 1980, em contraposição ao nacionalismo moralizante, queo ensino deH istória fosse um aliado consciente do compromisso político do professor, que socialmente deveria objetivar com o ato educativo a "igualização dos homens".

$\mathrm{O}$ ato educativo deveria estar dirigido ao objetivo de igualizar os homens em todos os níveis, de modo que não houvesse divisão social entreintelectuais eignorantes. Dirigida a esse objetivo, a instrução alteraria a constituição da sociedade, tornando-se um elemento político de mudança. A perspectiva educacional que objetivava a igualdade de todos os cidadãos exigia que diferentes formas e estímulos fossem encaminhados para instruir aquelesquejá tinham sido prejudicados pelo sistema econômico e político. Parecia ser lógico, aos dirigentes educacionais, que essa opção levaria a uma melhor qualidade de ensino, a qual não se restringia à exigência de fornecer a todo e qualquer usuário da educação o mesmo conjunto de conhecimentos. Essa opção exigia, ainda segundo seus idealizadores, a não-simplificação ou o não-barateamento dos conteúdos ministrados nas instituições escolares aos alunos das classes populares.

0 ideal de cumprir esses objetivos não poderia prescindir de uma formulação adequada das atividades escolares. $O$ discurso da SEED anunciava-se comprometido com os que necessitavam aprender. Declarava crer que a vida escolar deveria ser organizada em torno das atividades dos alunos, e pedia que o ambiente da escola oferecesse a maior variedade possível de situações produtoras de ensino. Pressupunha que a pessoa se apropria dos saberes por força da própria atividade, e não segundo a concepção de modelos e programas prefixados.

Tal discurso convidava o professor a participar da construção da prática escolar, partilhando com os demais interessadosa premissa de que:

Importa todo o universo de conhecimentos, já acumulados esistematizados pela humanidade. Mas muito mais importa que o aprendiz incorpo- 
re o conhecimento das regras de funcionamento da sociedade, sua origem, formação e reprodução. Importa também trabalhar um novo perfil do educador que leve em conta: a capacidade de trabalhar politicamente com outros educadores e animadores sociais; a visão pedagógica global e não somente de especialista; a capacidade de construir o ensino com os aprendizes, excluindo toda forma de condicionamento e dependência. Um educador crente e esperançoso numa sociedade de relações equânimes, construtor da educação como prática social, hábil em produzir ciência comprometida com o ganho cumulativo de vida e liberdade. ${ }^{14}$

Os conteúdos pretendidos, propostos pela Secretaria de Estado da Educação para o ensino deHistória, acabaram por ser sistematizados na formulação do Currículo Básico do Paraná15 e de materiais didáticos como os cadernos intitulados Lições do Professor, que pretendiam deixar claro quea proposta de trabal ho compreendia quea H istória poderia ser apreendida em três dimensões:

A História vivida: aquela que é vivida por nós, no presente e foi vivida por todos os homens no passado (organizados em classes, grupos e em sociedade). Essa H istória é objeto de estudo dos historiadores. A H istória produto da reflexão dos pesquisadores, estudiosos. É o conhecimento histórico acumulado - a historiografia. A História como matéria de ensino, isto é, o conteúdo que já foi selecionado do conjunto histórico produzido e que foi sistematizado para ser ensinado nas escolas. Nós, professores, ao trabalharmos com os nossos alunos, devemos ter consciência da necessidade da relação entre estas três dimensões: relacionando o conteúdo que estamos ensinando com a produção historiográfica mais avançada e ao mesmo tempo com a H istória que vivemos e com uma proposta de ensino de História. ${ }^{16}$

A Secretaria de Educação defendia insistentemente a obrigatoriedade de o professor priorizar, em suas ações pedagógicas, seu compromisso político, imprimindo uma diretriz ao seu fazer pedagógico. Essa postura, de certa forma imposta ao professor, pretendia ser uma força iluminadora na atuação de todos os envolvidos com o cotidiano escolar.

O discurso da SEED alicerçava-se na premissa de que a educação estava sendo repensada e resgatada como um ato político, e por conse- 
guinte suas conseqüências sociais não poderiam deixar de ser consideradas. Afirmava que os resultados do ensino são resultados políticos e quea atividade do professor, ao ensinar na escola, necessitava ser realizada como um compromisso político com a sociedade. A ação educativa estava sendo discutida e determinada pela Secretaria, pressupondo-a como um ato político, uma vez que sua prática tem conseqüências. "É um ato político porque orienta a ação humana, que é, e sempre foi, inspirada em opções políticas, filosóficas e ideológicas". ${ }^{17}$

De maneira coerente com essa postura, tomada mediante 0 ato de ensinar e suas conseqüências, a SEED definiu pressupostos que intencionavam estimular o entendimento, pelo professor, do compromisso político que as atividades escolares por ele desenvolvidas significavam. Reiterava essa idéia em todos os espaços de comunicação, tal como a seguir:

[...] como sabemos, a fonte de todos os tormentos na área educacional é essencialmente política e hoje situa-se no projeto político, de caráter nacional, responsável pela educação vigente no País. Resolver em profundidade os problemas candentes que a todos angustiam significa atacar a fonte primeira de sua ocorrência. ${ }^{18}$

A disciplina de H istória fora resgatada, por esseprojeto, como uma aliada. Recebeu destaque como detentora de saberes indispensáveis ao projeto político de sociedade quese formulava no período pós-ditadura militar. Caracterizá-la, a partir do projeto em análise, como uma solução milagrosa delibertação, seria um descuido analítico; entretanto, atribuía-se a ela a potencialidade da elevação direta do nível de consciência dos educandos. Por meio de seus conteúdos possibilitava ao educando que tomasse contato com uma forma de pensamento esclarecedor com relação à classe social a que pertencia, e de posse desses conhecimentos caberia ao aluno interferir na sociedade, como sujeito histórico, contribuindo para a sua transformação. Qualitativamente se estaria oportunizando o conhecimento de "níveis mais elaborados de abstração, o queé um dos requisitos para o exercício da cidadania". ${ }^{19}$

O discurso que embasa o Projeto Político-Pedagógico da SEED é coerente; entretanto, se isto for relacionado às ações concretas efetiva- 
mente realizadas, estas são mais modestas do que as intenções anunciadas. 0 conteúdo das propostas veiculado nos documentos é bastante repetitivo, chegando a ser enfadonho.

Os argumentos propostos como estratégias reflexivas, objetivando a elevação do nível educacional, remetem o leitor a um raciocínio de caráter solidário; o pedido é de participação, comunhão, humildade, dedicação, responsabilidade. Esta é a tônica do discurso. 0 teor argumentativo do projeto, quando discutequalidadedeensino, émessiânico, como se, respondendo às expectativas da SEED, a população pudesse conquistar uma nova sociedade, mais justa, mais fraterna, mais livre, com níveis de consciência mais elaborados.

0 Jornal da Educação, divulgador do projeto, apropriou-se de textos como o de D. Helder Câmara, utilizando-os como reforço para o enfoque pretendido. Assim, publicou:

\author{
Diante do colar \\ - belo como um sonho - \\ admirei, sobretudo \\ o fio que unia as pedras \\ e se imolava anônimo \\ para que todos fossem um...20
}

Dentro da mesma lógica, um discurso proferido por outro padre foi tomado pelo jornal como parâmetro elevado atéas escolas. D esta vez a pal avra de força erajustiça, e neste contexto os problemas educacionais vão, pela imposição da linguagem, tomando contornos nos quais a busca de solução para os problemas educacionais parece ser possível, se efetivada como problema defé. Esperava-se que o educador seposicionasse como uma pessoa presente na vida de seus alunos. Tal como numa profissão de fé, anunciava-se:

A educação para a justiça implica num compromisso com a construção de uma sociedade onde prevaleçam a participação e a comunhão [...] $M$ as, se durante todo o processo de educação formal, a criança e o jovem são tratados como incapazes de decidir sobre as coisas que lhes dizem respeito, não estaremos preparando pessoas dispostas a buscar essa mesma participação e comunhão em sociedade..21 
O sonho, algo tão particular, também foi resgatado deforma social, como argumento para reflexão sobre as questões educacionais.

Se o homem estivesse completamente privado da capacidade de sonhar, se não pudesse de vez em quando adiantar-se a contemplar em sua imaginação o quadro inteiramente acabado da obra que esboça em suas mãos, não poderia imaginar o que o obrigaria a empreender e levar a termo vastas e penosas empresas no terreno das artes, das ciências e da vida prática. 0 desacordo entre os sonhos e a realidade não produz dano al gum, sempre que a pessoa que sonha creia sinceramente em seu sonho. ${ }^{22}$

Construir a realidade a partir de seus sonhos, crer sinceramente nos sonhos... As afirmações sugerem que, durante o processo, o entusiasmo ea crença na nascente democracia como solução para todos os problemas era uma premissa que começava a ficar nos sonhos; ou ainda, dito de outra forma, manteve-se como elemento do discurso. Mas, e a tão sonhada, decantada qualidade de ensino que figurou no discurso educacional dessa época como elemento transformador da sociedade? Continuou a figurar, não mais como poder revolucionário, transformador, mas como possibilidade de formação moral, de conduta ética. A própria trajetória do Projeto Pedagógico dos anos 80 reforça a premissa de que não houve rompimento significativo na forma e tampouco no conteúdo do ensino de História: a busca continuou a ser moralizante e nacionalista.

A importância atribuída à disciplina de H istória, diante dos princípios humanistas e não mais políticos, foi estrategicamente substituída por uma súbita relevância dada à disciplina de desenho, por meio da qual se pretendia que 0 aluno, no conjunto das aquisições que a escola lhe proporcionava, pudesse interagir com o mundo, e não ser dominado por ele. Na perspectiva de uma atuação diferenciada do período ao qual se opunha, o ditatorial, a SEED ia criando ações em que o debate acerca de questões educacionais pudesse melhorar o ensino, ainda que a saída estivesse na fé. 0 que se passa a procurar já não é a glória de um projeto que se opunha aos "famigerados" anos da ditadura militar, mas uma identidade.

Na busca por essa identidade o tema da cidadania ocupou lugar de destaque, não somente nas discussões acadêmicas como também nos discursos políticos veiculados em defesa dos movimentos populares, tor- 
nando-se um dos conceitos mais utilizados à época. N unca se falou tanto em cidadania!

A nossa Constituição, ${ }^{23}$ em seu Título VIII, capítulo III, traz um artigo que faz alusão à questão da cidadania, em seu art. 205, determinando que a "educação, direito de todos e dever do Estado e da família, será promovida e incentivada com a colaboração da sociedade, visando ao pleno desenvolvimento da pessoa, seu preparo para o exercício da cidadania e sua qualificação para o trabalho".

Os Parâmetros Curriculares Nacionais indicam, como um dos objetivos do ensino fundamental, que os alunos sejam capazes de

[...] compreender a cidadania como participação social e política, assim como exercício de direito e deveres políticos, civis e sociais, adotando, no dia-a-dia, atitudes de solidariedade, cooperação e repúdio às injustiças, respeitando o outro e exigindo para si o mesmo respeito; bem como, a necessidade de conhecerem as características fundamentais do Brasil nas dimensões sociais, materiais e culturais como meio para construir progressivamente a noção de identidade nacional. ${ }^{24}$

Diante de proposições e pareceres acerca do tema, é preciso que se alerte para o risco de sua excessiva utilização. Conceitos aplicados de forma indiscriminada sem que se considerem as circunstâncias culturais, políticas e históricas que o envolvem acabam por sofrer um esvaziamento em seu sentido. As noções de cidadania, democracia e política são conceitos/categorias que, por freqüentarem assiduamente 0 discurso modernizante do século XX, assumiram significados por vezes com características excessivamente positivas. Quase como magia, esses termos se especificam no interior de projetos pedagógicos e contextos sociais diferentes. Assim, o documento que está sendo analisado pode ser entendido.

A relação entre o discurso proferido e a ação efetivada não é simples. A prática efetiva está entrecortada por motivos conflitantes entre os personagens implícitos no discurso que fundamenta o projeto político. As políticas formuladas por um órgão oficial estatal e as publicações da SEED são respostas oficialmente dadas às demandas geradas por grupos, por facções da sociedade. 0 teor do discurso é esperado. 0 conteú- 
do é redigido para atender a demandas específicas. Essas necessidades podem ser gestadas por vários segmentos, mas o projeto atenderá a apenas um deles. A equipe da Secretaria de Educação privilegia um discurso que se propõe a optar pelas maiorias carentes, pelos excluídos.

A equipe pedagógica constituída pela SEED, após o regime militar, orientou-se, num primeiro momento, pelas denominadas pedagogias progressistas. Entretanto, na contra-mão do discurso as outras instâncias governamentaisnão semantiveram em consonância com a Secretaria de Educação, ou seja, não houve o aparato necessário à manutenção dos compromissos assumidos em campanha; por exemplo, os professores tiveram seus salários arrochados. Com a sobrevivência ameaçada, como construir cidadania, como sentir-se positivamente participante de um projeto, quando se éa parte desfavorecida desse projeto?

Diante desses desafios o discurso toma nova formatação e se mistura a conteúdos de fé, trazendo à tona a velha idéia de que a profissão do educador se confunde com um sacerdócio; portanto pleno de resignação, determinação, humildade, com menos exigências, para ser exercido em prol do bem comum.

A reestruturação do sistema brasileiro de proteção social esteve no centro dos discursos sobre possíveis reformas a serem executadas durante os anos 1980. Embora tal década nascesse com o sonho de uma sociedade democrática, ela morre sem ter realizado as promessas que a inauguraram. Essa constatação, freqüentemente exposta aos olhos dos educadores, fez nascer um período de desencanto, contrariando a aposta na suposição de que o processo de democratização da escola aceleraria o caminho para a democratização da sociedade, com o conseqüente acesso à cidadania, o que não se efetivou, muito embora o discurso baseado nessa tese tenha se reconstituído durante as duas últimas décadas do século $X X$.

A instituição educativa não é um espaço neutro. Esta não é uma constatação nova. Seu espaço é disputado como palco para discursos ora de manutenção da ordem ora para sua mudança. Neste contexto de disputa pelo poder político, a educação se manifesta como elemento catalisador. Entendê-la como aceleradora de um processo faz com que seja constantemente resgatada. Nesta lógica, os conteúdos pertinentes ao ensino de H istória durante as últimas décadas, na forma di- 
tatorial ou na da democracia representativa, sempreatenderam ao ideal de nacionalidade.

O Estado, ao definir uma política educacional, percorre um longo processo de elaboração, até o fazer-se na prática educativa, nas unidades escolares. No caminho, o discurso por uma escola pública, gratuita, democrática e universal pode se manter, mas a prática que a efetivaria se segmenta nas esferas em que a educação se reproduz e se diferencia nas formas de apropriação desse discurso.

Também não se pode desconsiderar, como elemento dificultador de uma prática educacional mais próxima das expectativas dos agentes nela envolvidos, a ação de uma política clientel ista, que permeia a distribuição e a gestão dos recursos para a educação, em todos os seus níveis. Educa-se para atender a interesses. Educar é sempre criar adequação "a". Ou, dito de outra forma, é o aprendizado de um sistema de valores em curso, o que o sistema de ensino brasileiro tem tentado realizar, qualquer que seja a forma política de configuração do Estado, ditatorial ou democrático.

Atualmente pede-se à escola, e por conseguinte ao professor, que conceba seu fazer pedagógico com base na transmissão de valores, objetivando a transversalização em seus currículos e programas. Aprender valores em curso pode também ser definido como adestramento, formação do indivíduo para a obediência de regras e a incorporação de hábitos. Não é possível ser independente do mundo em que se vive. Somos o que conseguimos criar, inventar como sociedade. $\mathrm{N}$ ão se trata de condenar uma forma de vida, como se el a fosse estagnada. Como nunca vivenciamos o mundo da velocidade, do movimento, não há espaços nem definições que possam dar conta do que se denomina atual. Existe o espaço tangencial, aquele que foge à lógica da ciência, à formação acadêmica, e o encontro desse espaço é que nos desafia como pesquisadores/professores.

A escola, a despeito de ter sido aclamada duranteas décadas de 1980 e 1990 como uma possível redentora dos problemas sociais, definitivamente não o é. Ela funciona bem quando atende, sem qualquer "pretensão maior", ao mercado de trabalho. Entretanto, em nossos dias, ser detentor de saber sistematizado não garante a sobrevivência, o emprego, nem sequer a adequação dos indivíduos ao seu meio, o que permite afir- 
mar queo ensino deH istória tem ou teve pouquíssimaschances deexercer o poder que os vários projetos educacionais derivados de um único projeto de nação, o de criação de uma identidade nacional, Ihe conferiram.

As entidades brasileiras, formalmente organizadas em prol de uma educação pública, universal e gratuita, e de qualidade, reclamam insistentemente, junto aos seus governantes, uma ação que leve à educação para todos. Entra governo, sai governo e as promessas el eitoreiras não saem dos palanques. No caso das políticas educacionais, elas se definem como uma sofisticação dessas promessas.

Estamos no século XXI. O futuro chegou, e nossas reivindicações ainda passam por questões do início do século passado. Na entrada do período republicano no Brasil, José Veríssimo publicava a Educação Nacional, ${ }^{25}$ uma obra que estabelece, pela via educacional, três pilares para o desenvolvimento e progresso da nação brasileira. São el es: A Educação do Caráter, a Educação da Mulher ea H istória Pátria. Hoje, o discurso promovido pelos órgãos oficiais acerca da construção de uma sociedade democrática, mais cidadã, funda-se num apelo ao trabalho voluntário. 0 indivíduo é cada vez mais requisitado a prestar sua contribuição, eo discurso continua seduzindo pelo social. Projetos como "Amigos da Escola”, "Acorda Brasil! Está na hora da escola!", ${ }^{26}$ em que existe a oferta de atividades desde as mais simples até as mais sofisticadas, todas são bem-recebidas. 0 discurso em prol da cidadania, com base na formação do cidadão consciente de seus deveres e confiante em seus direitos, continua se ancorando num tom humanizador ecristão, baseado na solidariedade.

A educação tem vivido "uma guerra atômica sem o átomo, mas análoga pelo impacto". ${ }^{27} \mathrm{O}$ caminho percorrido intentou demonstrar que éfalaciosa a idéia de que está nas mãos dos educadores compromissados politicamente com sua nação a possibilidade de sua transformação, e de que o melhor ensino, ou o ensino de qual idade, seria aquele que aumenta e estimula a atividade do homem, que engendra a vida.

A crença em uma concepção teórica universalizante, totalizante, para se pensar, compreender e interferir na sociedade se revelou, ao longo do desenvolvimento do Projeto Político-Pedagógico proposto pela SEED, como um simulacro. Falou-se tanto em social que este se perdeu. Tentou-se, por meio de uma concepção teórico-metodológica imputar 
tudo ao social, exprimir todo o social, retirá-lo da dimensão representativa, e com isso ele se diluiu. Centrifugou-se.

RODRIGUES, Elaine. Reforming the teaching of History: lessons of continuity. História, v. 23 (1-2), p. 49-68, 2004.

A B ST R ACT : The teaching of History and the problem of its contents' continuity arediscussed. The themewas problematized at two important landmarks in Brazilian history. Whereas the aims of the discipline M oral and Civic Education show the dictatorial period, the post-dictatorial one is characterized by the (re)birth of democracy. Further, the political and pedagogical project of thestate of Paraná and its expectations in theteaching of History are provided. Since our research is based on comparative analysis, results show that the idea that a chasm exists between the form and contents of the teaching of $\mathrm{H}$ istory is misleading. They rather indicate that it is the job of teachers committed to their country to transform it. The Jornal de Educação, the law that established the discipline M oral and Civic Education, the Pedagogical Project and the Basic School Curriculum of the state of Paraná have been used as first sources.

KEYWORDS: History; The teaching of History; Moral and Civic Education.

\section{NOTAS}

${ }^{1}$ Professora Dra. do Departamento de Fundamentos da Educação da Universidade Estadual de Maringá-UEM - CEP-87020-900 Maringá - Paraná - Brasil. e-mail: elainerodrig@terra.com.br

2 BAUDRILLARD, Jean. A Ilusão do fim ou a Greve dos Acontecimentos. Lisboa: Terramar, 1992. Tradução de M anuela Torres, pp.7-8.

${ }^{3}$ NIETZSCHE, F.W. O bras incompletas: seleção de textos de Gerard Lebrun, tradução e notas de Rubens Rodrigues Torres, 5a ed. São Paulo: Nova Cultural, 1991, p.114.

${ }^{4}$ BARREI RO, José Carlos. Os Parâmetros Curriculares N acionais e os novos desafios da escola. In: História e cidadania - XIX Simpósio Nacional de História - AN PUH. 1998, p.584. 
${ }^{5}$ CN M C. Educação M oral eCívica, 1973, p.5-7.

${ }^{6}$ IBRASA. 0 cidadão e o civismo.1982, p.43-4.

7 PARAN Á, SEED. Currículo Básico para a Escola Pública do Estado do Paraná. Curitiba: SEED, 1990, p. 13.

${ }^{8} \mathrm{~A}$ proposta foi desenvolvida com rigor pelo professor Dermeval Saviani em sua formulação sobre a educação, denominada: "Pedagogia Histórico-Crítica". Sobre essa temática ele publicou vários títulos, o mais famoso dos quais é Escola e Democracia, que no de 1986 já estava em sua 11ạ edição. Em entrevista concedida a APP sindicato, no ano de 1997, o próprio professor Dermeval Saviani alerta sobre os riscos de se fazer uma adesão pré-critica a novas propostas educativas. São suas palavras: “Quando eu lecionava na pós-graduação e discutia a adesão pré-crítica a teorias pedagógicas, eu discutia até os próprios conceitos que nós trabalhávamos. Por exemplo, a filosofia da educação como reflexão radical e rigorosa do conjunto de problemas que a educação apresenta [...], muitas vezes 0 aluno recitava isto, e fazia uma adesão pré-critica. Por isto e a partir daquelas razões que eu dei o nome de Pedagogia Histórico-crítica, também não esteve imune a isto. Isto ocorreu no Paraná [...], esta concepção foi implantada no Paraná, na tentativa de se formular algo consistente, e a forma como isto foi sucumbindo posteriormente. Ocorreu uma adesão pré-crítica e foi tratada como moda. Houve um momento em que ela se difundiu e adquiriu uma certa hegemonia, sendo então abraçada como moda [...]. Hoje, às vezes, eu até digo: ainda bem que passou a moda," p.7-22.

${ }^{9}$ Neidson Rodrigues foi colaborador do Jornal da Educação editado pela SEED. Uma de suas matérias foi publicada no ano 2, n.5, p.6, jul./ago, 1984; publicou também Por uma nova escola: 0 transitório e o permanente na educação. São Paulo: Cortez, 1985, e ainda, Lições de Príncipe e outras lições. São Paulo: Cortez,1987. Da mistificação da Escola a escola necessária. São Paulo: Cortez, 1987.

${ }^{10}$ Ernesta, Zamboni discute essa questão no texto: Projeto pedagógico dos parâmetros curriculares nacionais: identidade nacional e consciência histórica. Caderno Cede, v.23, n.61, dez. 2003. A autora também discorda da idéia de que tenha havido uma ruptura na forma e no conteúdo do ensino de História em relação ao período anterior a 1964 e em sua seqüência após o golpe de 1964.

${ }^{11}$ LAVILLE, Christian. A guerra das narrativas: debates e ilusões em torno do ensino deHistória. Rev. Bras. H ist., 1999, v.19, n.38, p.125-138.

${ }^{12}$ FERRARINI, Sebastião. Armas, brasões e símbolos nacionais, 1979, p.15.

${ }^{13}$ PARANÁ, SEED. Fundamentos e explicitação das políticas da SEED, 1983, p.5-9.

${ }^{14}$ Idem. Jornal da Educação, Ano 3, n.9, mar/abr., 1985, p.12.

${ }^{15}$ Idem. Currículo básico para a escola pública do Paraná. Curitiba, 1990, p.81-97.

${ }^{16}$ Idem, Cadernos Lições do Professor, 1991, p.91 (grifo meu). 
${ }^{17}$ Idem. Jornal da Educação, mar. /abr., 1984, p.4.

${ }^{18}$ Idem. Ano 2, n.7, nov/dez. 1984, p.3.

${ }^{19}$ Idem, mar. /abr., 1984, p.10.

${ }^{20}$ Idem, jan. /fev., 1985, p.7.

${ }^{21}$ Idem, p.6.

${ }^{22}$ Idem, p.7.

${ }^{23}$ VITA, Álvaro de. N ossa Constituição. São Paulo: Ática, 1989, p.182.

${ }^{24}$ BRASI L. Secretaria de Educação Fundamental. Parâmetros Curriculares Nacionais: terceiro e quarto ciclos: apresentação dos temas transversais. Brasília: M EC/SEF, 1998, p.7.

${ }^{25}$ VERI SSI M O,J osé. A Educação nacional. 3ํed. Porto Alegre, M ercado Aberto, 1985. ${ }^{26}$ São projetos desenvolvidos pelo governo federal - M EC eabrangem todo o território nacional. 0 programaAmigos da Escola foi lançado no final dos anos 90 , sendo 0 mais conhecido dos exemplos. Conta com o apoio da RedeGlobo de Televisão. "Acorda, Brasil! Está na Hora da Escola!", foi criado em março de 1995: é um projeto que traz como slogan - "Brasil em ação" - Como contribuir para melhorar a escola pública. Incentiva a sociedade a assumir sua parcela de responsabilidade em relação à qualidade da escola e da Educação. Este projeto destaca, ainda: “Cada um de nós pode fazer muito pela escola, seja como profissional ou na condição de pais, avós, tios, etc. Fica mais claro a cada dia que as soluções dependem da ação de todos. 0 Acorda Brasil é muito mais de que um programa de mobilização. É um 'sentimento' participativo cotidiano que deve habitar cada cidadão." (Folder do Boletim Acorda Brasil, ano 1, n.1, 1997).

${ }^{27}$ BAU DRILLARD, Jean. 0 p. cit., p.89-91.

Artigo recebido em 07/2004. Aprovado em 09/2004. 